\title{
Heterotopic Growth of Dysplastic Cerebellum in Frontal Encephalocele in an Infant of a Diabetic Mother
}

\author{
HAR VEY B. SARNAT, DAPHNE E. deMELLO, JOHN D. BLAIR, and SAEEDA Y. SIDDIQUI
}

SUMMARY: An infant of a diabetic mother lived 13 days after birth. She had a small dysplastic $12.6 \mathrm{gm}$. brain, partly forming a frontal encephalocele. The uncleaved forebrain contained a mass of poorly organized heterotopic cerebellar cortex. The cerebellum itself had normal lamination, but was small and continuous with the dysplastic tissue. The ventricular system was absent except for a few midline ependymal rosettes, and the cerebral cortex was not developed. The cerebellar dysplasia resembled a proliferative and invasive lesion by its rostral extension.

RESUME: L'enfant d'une mère diabétique a survécu 13 jours après la naissance. Elle avait un petit cerveau dysplasique de $12.6 \mathrm{~g}$, partiellement contenu dans un encéphalocèle frontal. Le cerveau frontal non fendu contenait une masse de cortex cérébelleux hétérotopique mal organisé. Le cervelet lui-même avait une lamination normale, mais était petit et contenu avec le tissu dysplasique qui imprégnait le cerveau frontal. Le système ventriculaire était $a b$ sent sauf pour quelques rosettes épendymaires sur la ligne médiane, et le cortex cérébral n'était pas développé. La dysplasie cérébelleuse ressemblait à une lésion proliférative par son extension rostrale.

From the Departments of Paediatrics (Neurology) and Pathology, University of Calgary Faculty of Medicine, Calgary, Alberta and the Department of Pathology, Saint Louis University School of Medicine, St. Louis, Missouri, USA.

Reprint Requests to: Dr. Sarnat, University of Calgary Faculty of Medicine, Alberta Children's Hospital, 1820 Richmond Road, S.W., Calgary, Alberta, T2T 5C7

\section{INTRODUCTION}

Malformations of the nervous system are not uncommon in infants of diabetic mothers. The following case is a description of a severe cerebral dysgenesis and frontal encephalocele in such an infant, associated with heterotopic and dysplastic cerebellar cortex extending as far rostrally as the telencephalon and resembling a proliferative and invasive lesion.

\section{CLINICAL HISTORY}

A 4000 gram infant girl was delivered by Caesarean section at 36 weeks gestation to a 32 year old gravida 2 para 2 , juvenile diabetic who had taken lente insulin since 12 years of age. Apgar scores were 2 and 3 at one and five minutes. The infant had respiratory distress and several anomalies including a frontal encephalocele. Blood glucose a few minutes after delivery was $4 \mathrm{mg}$. per $\mathrm{dl}$. and she received a dextrose infusion. Intubation and respiratory support were given.

Neurologic examination on the second day revealed generalized hypotonia, brisk tendon reflexes, and poor Moro and suck reflexes. Eye movements were dysconjugate and continuously roving. Pupils were $3 \mathrm{~mm}$. and responded sluggishly to light. A persistent pupillary membrane was present. Responses to peppermint olfactory stimuli were not observed, but cranial nerve functions were otherwise intact. She shut her eyes in response to bright light, but did not visually fixate. The infant withdrew from painful tactile stimuli. Circumference of the head was $34.5 \mathrm{~cm}$. Transillumination was increased on all sides. The anterior fontanelle was $4 \times 5 \mathrm{~cm}$. and full.

Episodes of tonic stiffening of the body were observed. Electroencephalograms at 2 and 3 days of age were isoelectric. Serum calcium con- centration at 2 days of age was $3.7 \mathrm{mE}$ q./l., and calcium gluconate was given. The infant was thought to have pulmonic stenosis. Multiple hemivertebrae were demonstrated radiographically. The karotype was $46 \mathrm{XX}$ in cultured fibroblasts. She gradually became obtunded and died 13 days after birth.

Family history revealed no previous malformed infants or neurologic disease. A sibling was normal.

\section{GENERAL PATHOLOGIC FINDINGS}

External examination revealed a midline frontal encephalocele, hypotelorism, micro-ophthalmia, flattening of the nasal bridge, a short neck, absence of both external ears with a left preauricular skin tag, and micrognathia (Fig. 1). The patient also had kyphoscoliosis, multiple hemivertebrae, and wide separation between the first and second toes bilaterally.

A midline fused kidney was present, with a single ureter. The large heart had biventricular hypertrophy and infundibular pulmonic stenosis. A persistent left superior vena cava opened into the coronary sinus. Islet cell hypertrophy was demonstrated microscopically in the pancreas.

Samples of skeletal muscle from several sites were histologically normal. The quadriceps femoris was studied histochemically with adenosine triphosphatase (ATPase) and nicotinamide adenine dinucleotide tetrazolium reductase (NADH-TR). Muscle fiber types were well differentiated, in a mosaic distribution, and without smallness or predominance of either type.

The placenta was not available for examination. 


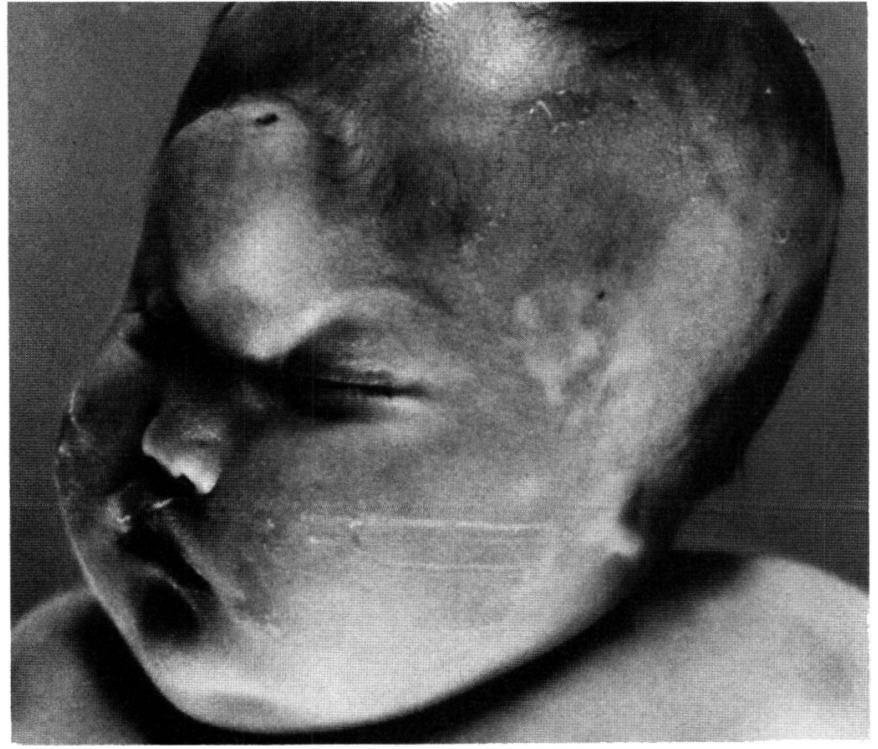

Figure 1 - Postmortem photograph of infant showing frontal encephalocele. Ears were absent.

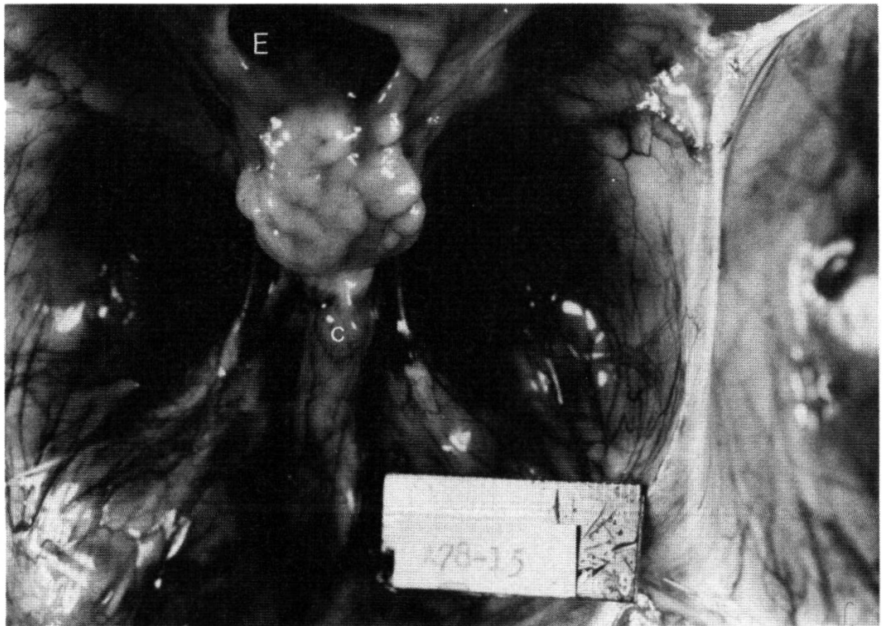

Figure 2 - Brain in situ, showing well developed base of the skull with bones of calvarium reflected. The light-coloured tissue forming pseudogyri on the dorsal surface of the brain is dysplastic cerebellar cortex. It is continuous with the small cerebellum dorsal to the brain (C). The forebrain extends into the encephalocele sac (E).

\section{NEUROPATHOLOGIC FINDINGS GROSS:}

A small brain at the base of the skull extended into the encephalocele sac (Fig. 2). The brain and spinal cord were removed intact as a single unit, and had a combined weight of 22.8 grams. When separated from the spinal cord, the brain weighed 12.6 grams. Dura and leptomeninges were identified. The subarachnoid space occupied most of the intracranial volume, and was filled with 300 to $400 \mathrm{ml}$. of clear fluid. The cerebrum measured $5.3 \times 2.3 \mathrm{~cm}$. The surface was irregular, and gyri were not formed. Solid forebrain tissue extended into the encephalocele sac. Olfactory bulbs and tracts were not identified. The optic nerves were small and entered the ventrolateral part of the brain after formation of an optic chiasm. The brainstem was thin and the medulla was not demarcated from the upper cervical spinal cord. The cerebral peduncles, basis pontis, and pyramids were not developed. Trigeminal and acoustic nerves were identified. A tiny $0.6 \times 0.6 \mathrm{~cm}$. cerebellum was present dorsal to the pons; a few folia were seen, but lateral hemispheres were not developed. A thin membrane covered the cerebellum and was continuous rostrally with the tissue on the dorsal surface of the brain.

The spinal cord was $14.8 \mathrm{~cm}$. in length and grossly normal. A filum ter- minale was present. There was no evidence of dysraphism.

Coronal sections of the entire brain disclosed solid parenchyma in the forebrain and encephalocele, without a ventricular system. The cerebral hemispheres were fused. Dark tissue surrounded the paler parenchyma of the forebrain (Fig. 3).

\section{MICROSCOPIC:}

Representative sections were stained with hematoxylin and eosin (H\&E), luxol fast blue and periodic acid-Schiff reagent (LFB-PAS), phosphotungstic acid-hematoxylin (PTAH), and SevierMunger silver stain. Selected sections also were stained with the GolgiKopsch technique. After removal of paraffin, a portion of the lesion of the forebrain was embedded in epon and sections of $1 \mu \mathrm{m}$. were cut and stained with toluidine blue. This tissue was unsatisfactory for electron microscopic interpretation.

The leptomeninges covering the hypoplastic brain and lining the calvarium were thick and focally consisted of loose mesenchyme and thinwalled blood vessels. Sections of sacral, lumbar, thoracic, and cervical spinal cord were histologically normal, except for absence of corticospinal tracts. The dorsal columns were well myelinated. A central canal was well formed.

The ventricular system had failed to develop. A few ependymal rosettes were seen in the midline of the diencephalon and mesencephalon. A space between the cerebellum and medulla contained loose connective tissue and large thin-walled blood vessels, but an ependymal lining was lacking (Fig. 4). Instead, a gliotic membrane covered externally by ependyma extended over the entire cerebellar cortex (Fig. 4). Villi of choroid plexus were found outside this membrane.

A tiny cerebellum appeared to consist of a vermis only (Fig. 4). It was normally laminated, including a prominent external granular layer, 8 to 10 cells thick. The molecular layer was thin. Purkinje cells were small with scant cytoplasm and large, vesicular, nucleolated nuclei. The internal granular cell layer was thin and loosely packed. Glomeruli were not well formed. Granular cells also were found heterotopically on the dorsal surface of the medulla (Fig. 4). The cerebellar white matter was lightly myelinated.

Foci of incompletely migrated inferior olivary neurons were present in the dorsolateral part of the medulla. The basis pontis and pyramids were rudimentary, although a small cluster of neurons in the midline near the basal sulcus of the brainstem probably were pontine nuclei. A poorly developed dentate nucleus was identified. The trigeminal nerve, its descending nucleus 


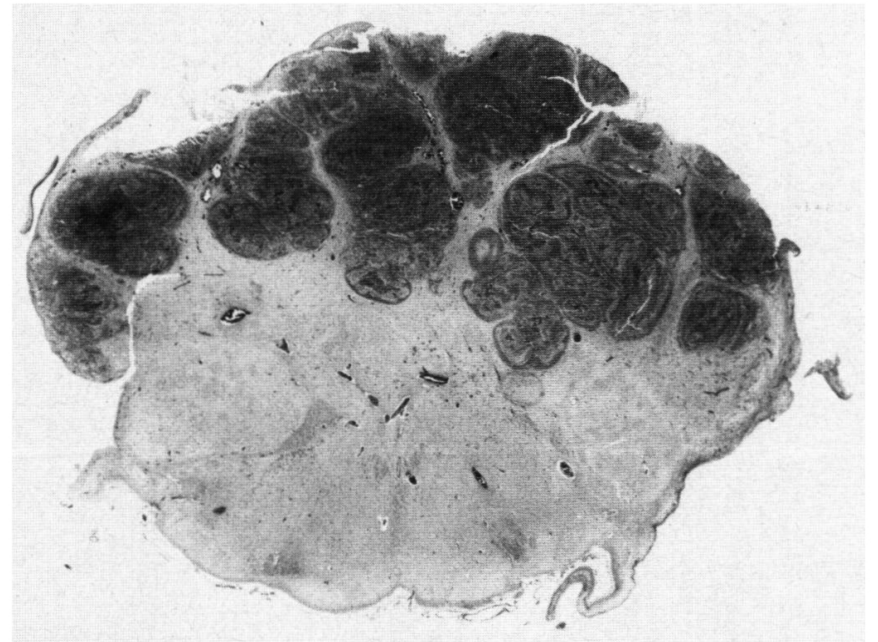

Figure 3 - Coronal sections of entire brain. Junction of encephalocele, at level of diencephalon, dysplastic cerebellar tissue covers or replaces cerebral parenchyma normally found. Hematoxylin-eosin. X 18.

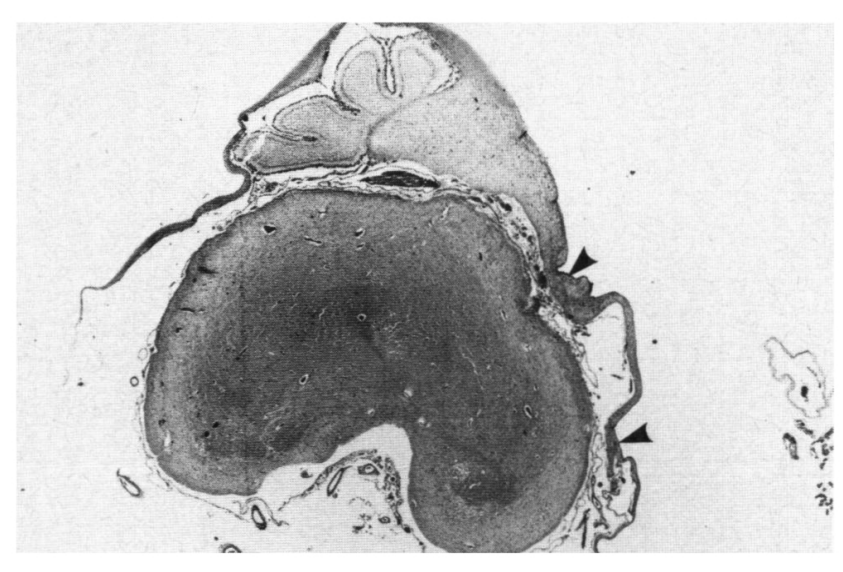

Figure 4 - Coronal sections of pons and hypoplastic cerebellum with normal lamination. A gliotic membrane containing portions of cerebellar cortex covers the cerebellum. The space between cerebellum and medulla is occupied by loose connective tissue and thin-walled blood vessels. External granular cells line ventral surface of cerebellum and dorsal surface of the medulla. Ependyma lines part of the membrane covering cerebellum and pons (arrowheads). Hematoxylin-eosin. X 18 . and motor nucleus, and well myelinated axons of the descending tract and motor root were demonstrated. The medial longitudinal fasciculus was large and well myelinated. The acoustic nerve was well developed. Myelinated fibers decussating in the ventral part of the pontine tegmentum constituted a trapezoid body.

The thalamus and basal telencephalic nuclei were poorly formed. The neurohypophysis and adenohypophysis were well developed and histologically normal. The cerebral hemispheres were fused, and a laminar cortex could not be identified in any part. Scattered calcifications were found in the parenchyma and within the walls of some vessels of the forebrain. Focal telangiectases also were present, with neurons and glia between numerous thin-walled, dilated blood vessels of variable size. A few small foci of fresh hemorrhage were seen, but zones of necrosis were not found.

Tissue having the appearance of dysplastic cerebellar cortex extended rostrally from the cerebellum dorsal and lateral to the diencephalon, and then entered the forebrain (Fig. 3). This tissue consisted of haphazardly aligned rows and nests of disorientated ganglion (probably Purkinje) cells, and irregular layers of small dark round cells, often forming rosettes as in the internal granular layer of the cerebellum (Fig. 5). In some areas, these dark round cells became spindle-shaped, with elongated nuclei. Pleomorphism was not otherwise seen, and mitoses were not encountered. Abnormal inclusions were not seen.

In the most rostral part of the forebrain, which had been contained within the encephalocele sac, a large densely cellular zone in the midline contained the subependymal germinal matrix of small dark round neurons.

Epoxy resin-embedded sections of 1 $\mu \mathrm{m}$. showed a single thick process arising from each large ganglion cell of the dysplastic tissue. This process sometimes divided into two branches, but the highly differentiated dendritic tree of the mature Purkinje cell was not identified in these preparations or with Golgi impregnations.

\section{DISCUSSION}

The identification of the dysplastic neural tissue as cerebellar rather than cerebral in origin is based on several pathologic features: 1) It is anatomically continuous with the diminutive cerebellum above the brainstem; 2) It proliferated into the midbrain and diencephalon more than it involved the forebrain; 3) The large ganglion cells forming a poorly organized lamina closely resemble Purkinje cells in size, shape, and cytologic detail, and are unlike pyramidal Betz cells or other large cerebral cortical neurons; 4) The small dark round cells resemble cerebellar granular cells, and form rosettes and glomeruli rather than orienting themselves in laminae as they would in the middle layers of the cerebral cortex.

The external granular layer originates at the germinal trigone (formerly rhombic lip) and spreads rostrally and laterally over the developing cerebellum. This development occurs after the Purkinje cells and neurons of the deep cerebellar nuclei already have differentiated (Das and Nornes, 1972; Altman and Bayer, 1978). The heterotopic layer of ependyma over the surface of the cerebellum in our case accounts for the presence of choroid plexus external to the brain. Choroid plexus forms by the apposition of neuroepithelium and mesenchyme; an example of normal extraventricular choroid plexus is the paraphysis, derived from the roof of the third ventricle in lower vertebrates and mammalian embryos (Netsky and Shuangshoti, 1975).

In 1920, Lhermitte and Duclos described a proliferative lesion of the cerebellar cortex as a 'diffuse ganglioneuroma'. Only fourteen additional cases have been reported subsequently (Ambler et al., 1969; Christensen, 1937; Courville, 1958; Duncan and Snodgrass, 1943; Foerster and Gagel, 1933; Hallervorden, 1959; Oppenheimer, 1955; Pritchett and King, 1978; Simeoni, 1966), but none were associated with encephalocele or 


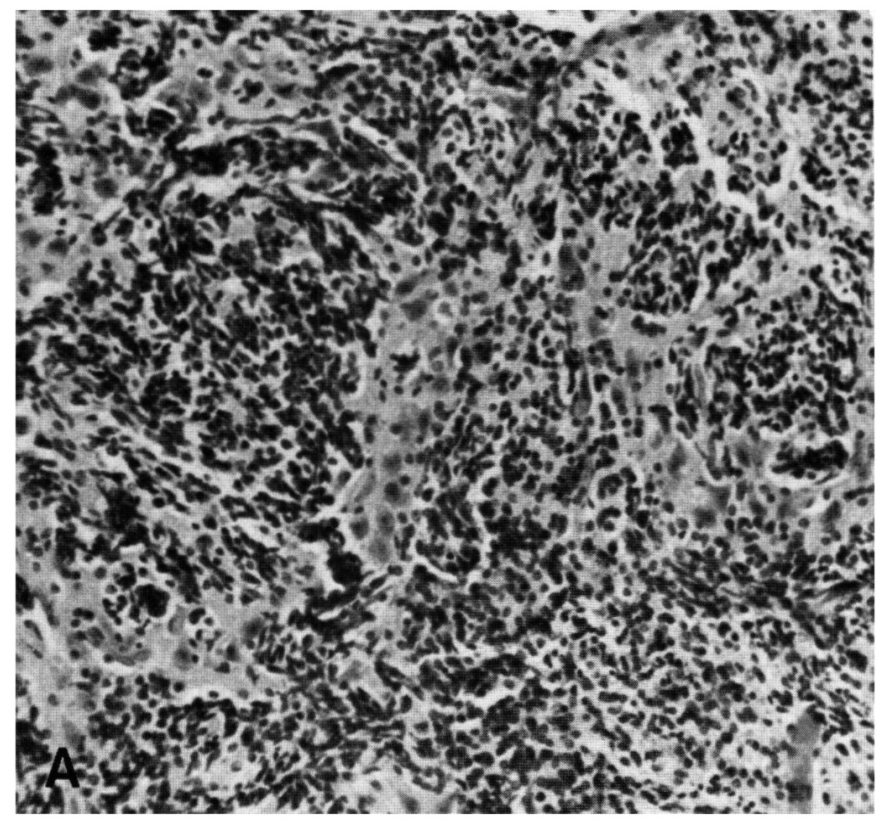

Figure 5 - Dysplastic cerebellar tissue in forebrain consists of poorly aligned rows and nests of Purkinje cells and granular cells. The small dark cells are either round or spindle-shaped, and in places form loose

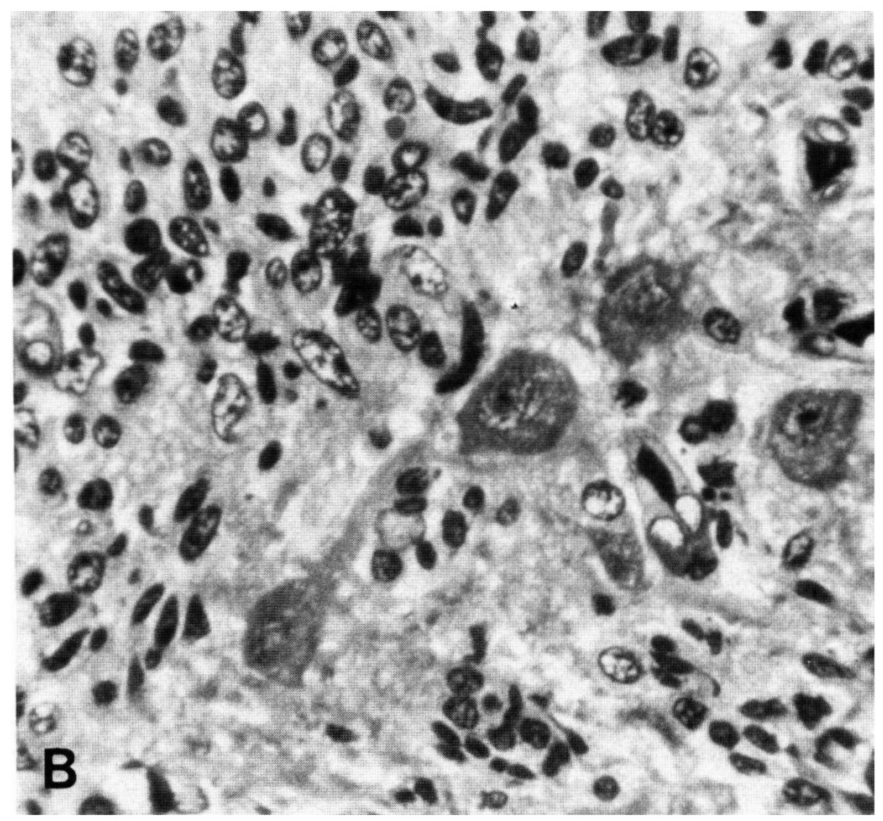

rosettes. Many large ganglion cells have a massive apical dendrite. (A) paraffin section, H\& E, X 150; (B) l $\mu$ m epoxy resin section, toluidine blue, $X 400$ (original magnifications). other cerebral malformations. Most authors have applied the term 'dysplastic gangliocytoma' of Foerster and Gagel (1933), implying uncertainty of whether the pathologic process is fundamentally dysplastic (i.e. hamartomatous) or neoplastic in nature. Although the proliferative cerebellar lesion in our case is similar, we prefer to avoid this ambiguity because we consider it to be primary dysplasia and heterotopia.

A more appropriate classification of the proliferative lesion in this case might be 'cerebellar polymicrogyria', since it is a dysplasia of the cerebellar cortex. This term is usually applied to small focal nonproliferative lesions, most commonly at the margins of the cerebellar vermis. It is also not an entirely satisfactory term because cerebellar polymicrogyria does not necessarily exhibit excessive folding or abnormally small folia, and it is an attempt to apply a description of a cerebral dysplasia to the cerebellar cortex which is not comparable in development or organization (Friede, 1975). Larger zones of these cerebellar dysplasias also are described, sharply demarcated from adjacent normal cerebellar cortex. They may occur as solitary lesions of the brain or with other cerebral malformations usually associated with in- trauterine infections. Disorganized cerebellar cortical tissue commonly is found in occipital, but not frontal, encephaloceles (Friede, 1975). Granular cells may proliferate within suprasellar neoplasms, this neuronal type thus showing a high potential for differentiation and duplication in heterotopic sites within the brain (Friede and Yasargil, 1977).

Failure of the telencephalic hemispheres and ventricular system to form probably is part of a primary dysgenesis also involving the brainstem and associated with dysmorphic features of other organ systems in this infant of a diabetic mother. The absent olfactory bulbs and tracts and hypotelorism suggest that an extreme of holoprosencephaly may be the primary malformation of the telencephalon. This and other dysplasias of the forebrain, such as septo-optic dysplasia, occur in higher than random incidence in the presence of maternal diabetes mellitus (Dekaban and Magee, 1958; Donat, 1981). It is less likely that the proliferating cerebellar tissue invaded and destroyed the primitive germinal matrix of the forebrain because of the absence of necrosis and the presence of the encephalocele, the cluster of residual germinal matrix cells in the midline of the anterior part of the telencephalon, and the vascular malformations in this part of the brain. Furthermore, the anterior neuropore closes and the optic vesicles form ten days before the cerebellum normally develops in man.

Encephaloceles often are associated with extensive deformities of the cerebral hemispheres (Karch and Urich, 1972). Distortion and fusion of ventricular walls, hydrocephalus, agenesis of the corpus callosum, and proliferative vascularity may coexist (Friede, 1975). An inverse relation occurs between the size of an encephalocele and the degree of hydrocephalus (Masters, 1978). In our patient, who lacked a ventricular system, the hydrocephalus was external to rather than within the brain, augmented by external choroid plexus.

Finally, the well formed clivus and basal fossae of the skull, contrasting with the poorly developed brain, indicate that the chondrocranium, formed during the sixth and seventh weeks of embryonic life, develops more under genetic influence than as a result of induction or stimulation by the growing brain. The membranous calvarium underwent relatively normal growth because of pressure exerted by the intracranial fluid, similar to the expansion of the cranial vault in infants 
with hydranencephaly or end-stage fetal hydrocephalus.

\section{ACKNOWLEDGEMENT}

The authors are grateful to Martin G. Netsky, M.D., Professor of Pathology (Neuropathology), Vanderbilt University School of Medicine, Nashville, Tennessee; and A. Julio Martinez, M.D., Associate Professor of Pathology, University of Pittsburgh School of Medicine; for reviewing this case and offering helpful suggestions.

\section{REFERENCES}

ALTMAN, J., BAYER, S.A. (1978). Prenatal development of the cerebellar system in the rat. I. Cytogenesis and histogenesis of the deep nuclei and cortex of the cerebellum. $J$ Comp Neurol, 179: 23-48.

AMBLER, M., POGACAR, S., SIDMAN, R. (1969). Lhermitte-Duclos disease (granule cell hypertrophy of the cerebellum). Pathological an lysis of the first familial cases. J. Neuropatl ol Exp Neurol, 28: 622-647.

CHRISTENSEN, E. (1937). Über GanglienzelIgeschwülste im Gehirn. Virchows Arch Path Anat, 300: 567-581.

COURVILlE, C.B. (1958). Gangliocytoma myelinicum of the cerebellar cortex. Bull Los Angeles Neurol Soc, 23: 72-80.
DAS, G.D., NORNES, H.O. (1972). Neurogenesis in the cerebellum of the rat: An autoradiographic study. Z Anat Entwickl-Gesch, 138: 155-165.

DEKABAN, A.S., MAGEE, K.R. (1958). Occurrence of neurologic abnormalities in infants of diabetic mothers. Neurology, 8: 193-200.

DONAT, J.F.G. (1981). Septo-optic dysplasia in an infant of a diabetic mother. Arch Neurol, 38: 590-591.

DUNCAN, D., SNODGRASS, S.R. (1943). Diffuse hypertrophy of the cerebellar cortex (myelinated neurocytoma). Arch Neurol Psychiat, 50: 677-684.

FOERSTER, O., GAGEL, O. (1933). Ein Fall von Gangliocytoma dysplasticum des Kleinhirns. Ztschr $\mathrm{f} d \mathrm{~d}$ ges Neurol u Psychiat, 146: 792-803.

FRIEDE, R.L. (1975). Developmental Neuropathology. Springer-Verlag, NY, Vienna, pp 236-239, 326-338.

FRIEDE, R.L., YASARGIL, M.G. (1977). Suprasellar neoplasm with a granular cell component. J Neuropathol Exp Neurol, 36: 769-782.

HALLERVORDEN, J. (1959). Über die Hamartome (Ganglioneurome) des Kleinhirns. Dtsch Ztschr Nervenhk, 179: 531-563.
KARCH, S.B., URICH, H. (1972). Occipital encephalocele: A morphologic study. J Neurol Sci, 15: 89-112.

LHERMITTE, J., DUCLOS, P. (1920). Sur un ganglioneuroma diffus du cortex du cervelet. Bull Assoc Franç Cancer, 9: 99-107.

MASTERS, C.L. (1978). Pathogenesis of encephalocele and anencephaly: Relationship to the ventricular system and the significance of hydrocephalus. J Neuropathol Exp Neurol, 37: 656.

NETSKY, M.G., SHUANGSHOTI, S. (1975). The Choroid Plexus in Health and Disease. Univ. Press of Virginia, Charlottesville.

OPPENHEIMER, D.R. (1955). A benign "tumor" of the cerebellum. Report on two cases of diffuse hypertrophy of the cerebellar cortex with a review of nine previously reported cases. J Neurol Neurosurg Psychiat, 18: 199-213.

PRITCHETT, P.S., KING, T.I. (1978). Dysplastic gangliocytoma of the cerebellum. An ultrastructural study. Acta Neuropathol, 42: $1-5$.

SIMEONI, S. (1966). Il gangliocitoma displastico del cervelleto. Giorn Ital di Patologia e Scienze Affini, 13:1-46. 